\title{
Acromial morphology and morphometry associated with subacromial impingement syndrome
}

\author{
Thawanthorn Chaimongkhol ${ }^{1}$, Sirapat Benjachaya ${ }^{1}$, Pasuk Mahakkanukrauh ${ }^{1,2,3}$ \\ ${ }^{1}$ Department of anatomy Faculty of Medicine, Chiang Mai University, Chiang Mai, ${ }^{2}$ Forensic Osteology Research Center, Faculty of Medicine, Chiang \\ Mai University, Chiang Mai, ${ }^{3}$ Excellence Center in Osteology Research and Training Center (ORTC), Chiang Mai University, Chiang Mai, Thailand
}

\begin{abstract}
Acromion is a major associated structure of subacromial impingement syndrome, one of the most common diagnoses in chronic shoulder pain world-wide. The aims of this study are to study morphometry of acromion and to find risk group using acromial morphometry. Total samples were 392 scapulae. The samples were of both sexes, ranging from the age of 31 to 90 . Acromion type and osteophytes were observed. Acromial parameters were measured. The relationships were analyzed among acromion type, acromial osteophyte, acromial parameters, age group, sex and side. Curved acromion had the highest prevalence in all age groups. Hooked acromion had the second highest prevalence since the age of 41 . Hooked acromion prevalence was higher in male than in female. The highest prevalence of acromial osteophytes was on anteroinferior surface in all age group. The prevalence of acromial osteophytes on anteroinferior surface and acromial facet increased with age. In addition, acromion type was associated with only osteophytes on anteroinferior surface of acromion. Anterior one-third acromial thickness in the age of 31 to 50 was different from those of 51 to 90 . There are differences between all parameters and sexes, but not side. General population with age above 50 and concerned male group with age above 40 who have chronic shoulder pain should be investigated for subacromial impingement syndrome. Surgical treatment is recommended because hooked acromion and osteophytes are mostly the root of problem.
\end{abstract}

Key words: Acromion, Shoulder pain, Shoulder impingement syndrome, Subacromial impingement syndrome, Osteophyte

Received June 30, 2020; Revised August 2, 2020; Accepted August 24, 2020

\section{Introduction}

Chronic shoulder pain is one of the most common complaints of patients world-wide, especially in older age groups. The incidence peaks at the age of 60 to 69 . The prevalence of shoulder pain ranges from $7 \%$ to $34 \%$ in the general population $[1,2]$. Shoulder impingement syndrome (SIS) is one of

Corresponding author:

Pasuk Mahakkanukrauh (1D

Excellence Center in Osteology Research and Training Center (ORTC),

Chiang Mai University, Chiang Mai 50200, Thailand

E-mail:pasuko34@gmail.com the most common diagnoses in shoulder disorders causing chronic shoulder pain. Its prevalence ranges from $36 \%$ to $74 \%$ of patients [1-4]. This syndrome, if left untreated, could result in rotator cuff disruption which then persists to cause secondary osteoarthritis of the shoulder, severely restricting shoulder movement in the end [5]. There are 4 types of SIS, which are subacromial, coracoid, internal, and suprascapular nerve impingement. Almost all diagnosed shoulder impingement syndrome is subacromial type. Other types are very rare $[1,2,5,6]$. Subacromial impingement syndrome (SAIS) is the syndrome associated with compression and inflammation of supraspinatus tendon as it passes through subacromial space. SAIS is mostly diagnosed in the sixth decade of life $[1,3,4]$. This syndrome usually causes pain on arm elevation

\section{Copyright (c) 2020. Anatomy \& Cell Biology}

This is an Open Access article distributed under the terms of the Creative Commons Attribution Non-Commercial License (http://creativecommons.org/licenses/by-nc/4.0/) which permits unrestricted non-commercial use, distribution, and reproduction in any medium, provided the original work is properly cited. 
thus limits range of motion of the arm $[5,6]$. In some cases, the symptoms are relieved by conservative treatment alone. Although, some patients with specific structural pathology, such as bone spur of acromion or compression of acromial undersurface, might require surgical procedure, such as acromioplasty for definitive treatment [1, 7-10]. As for now, there has not been a clear demonstration of SAIS pathogenesis. There are 2 proposed mechanisms which are intrinsic and extrinsic mechanism $[5,7]$. In the extrinsic mechanism, acromion is one of the structures involved in causing SAIS $[1,5,11]$. Thus, the morphology and other parameters of the acromion are interesting to study.

There are previous studies in dry bone about acromial morphology related to SAIS and rotator cuff defect. Osteophyte formation was shown correlated with increased acromial curvature in increasing age. The difference between left and right acromion was significant. Osteophytes were found more on the right acromion. The variation of acromial parameters, such as acromial angle and acromial osteophyte, was associated with type of acromion. Furthermore, the type of acromion and osteophytes were related to SAIS. Especially, type III or hooked acromion was an important risk factor for osteophyte formation, SAIS and rotator cuff tear [8, 12-18]. However, conflicting results are demonstrated in some studies. Variations of acromial morphology were not acquired from degenerative changes and osteophyte formation. Also, degenerative changes were not related to SAIS. Acromial morphology was not different between sexes and sides of the shoulder [19, 20]. The studies of acromial morphology were carried out by X-ray, computed tomography (CT) scan, and magnetic resonance imaging (MRI) as well. Conflict in the association of acromial morphology and SAIS was still present. Morphology of acromion differed between left and right shoulder and between sexes [21]. It also differed between patients with degenerative rotator cuff tears and individuals without rotator cuff pathology [11]. Acromion type was shown correlated with age [22]. Low acromial tilt (AT) angle is related to SAIS [23]. Acromioclavicular osteophytes play an important role in causing SAIS [24]. But conflicting results are demonstrated in some studies that acromion type and parameters were not related with increased risk of SAIS and rotator cuff tear. The sexes were not related to any acromial parameters $[25,26]$. However, there were some limitations in using imaging study rather than dry bone. For example, patient position and motion might affect the quality of $\mathrm{X}$ ray, CT scan, and MRI images. Moreover, when considered as a whole, dry bone measurement is more cost-effective when compared to imaging study. The variations of acromial morphology were different among races [27]. Thus, it is important to study dry bone for the morphology of acromion in Thai population and using it to correlate with SAIS.

Therefore, the aims of this study are to study morphometry of acromion in Thai population, and to find SAIS risk group in Thai population using acromial morphometry.

\section{Materials and Methods}

All donated skeletons were selected from the Center for Forensic Science, Faculty of Medicine, Chiang Mai University. The samples were of both sexes, ranging from the age of 31 to 90 . Exclusion criterion is bony damage or pathologic disease on one or both sides scapulae, such as traumatic fracture. The samples were classified into 6 age groups. The sample size was calculated by one-sample mean formula $(\mathrm{a}=0.01, \mathrm{z}=2.58, \mathrm{e}=0.05)$ using data from pilot study with 10 samples from each age groups. The amount of sample would be 392 dry scapulae from 196 skeletons. There would be 32 samples in the age of 31 to 40,72 samples in the age of 41 to 50,72 samples in the age of 51 to 60,72 samples in the age of 61 to 70,72 samples in the age of 71 to 80 , and 72 samples in the age of 81 to 90 .

Both sides scapulae were inspected to describe anatomical morphology and data were recorded. The acromion was classified into 3 types. According to Bigliani et al. [28], flat acromion process, curved acromion process and hooked acromion process were type I, II, and III, respectively. The location of acromial osteophytes was classified into 3 main areas, anteroinferior surface, lateral surface and acromial facet. There were 2 types of acromial osteophyte, traction type and claw type. The traction type osteophytes were straight, and the claw type osteophytes were curved or hooked [17]. Then, acromial parameters were measured by digital Vernier Caliper and protractor. Each parameter was measured three times and averaged.

The following were 7 acromial parameters in this study. First, the maximum acromial length (APL) was measured from the tip of acromion process up to acromial angle along the middle of the acromion. The maximum acromial width (MLL) was measured from lateral aspect of acromion to its medial side across the middle of the acromion. Next, the anterior one-third thickness (TA) was measured at a point 1 centimeter from acromial tip. The coracoacromial distance 
(CAD) was the distance from the tip of acromion to superior edge of coracoid process. The supraglenoacromial distance (SAD) was the distance between the top of supraglenoid tubercle and the inferior surface of acromial tip. Finally, the AT was the angle of the line drawn along inferior edge of acromion from anterior to posterior side and the line drawn from inferior tip of coracoid process to inferior edge of acromion (Fig. 1). This angle was measured using a protractor when the scapula was set in lateral view.

The IBM SPSS Statistics for Windows, Version 22.0 (IBM Co., Armonk, NY, USA) was used to analyze the data. Samples were stratified into 6 age groups, with 10 years in each group. The prevalence of acromion type and acromial osteophytes in each area were calculated. Mean of each pa-
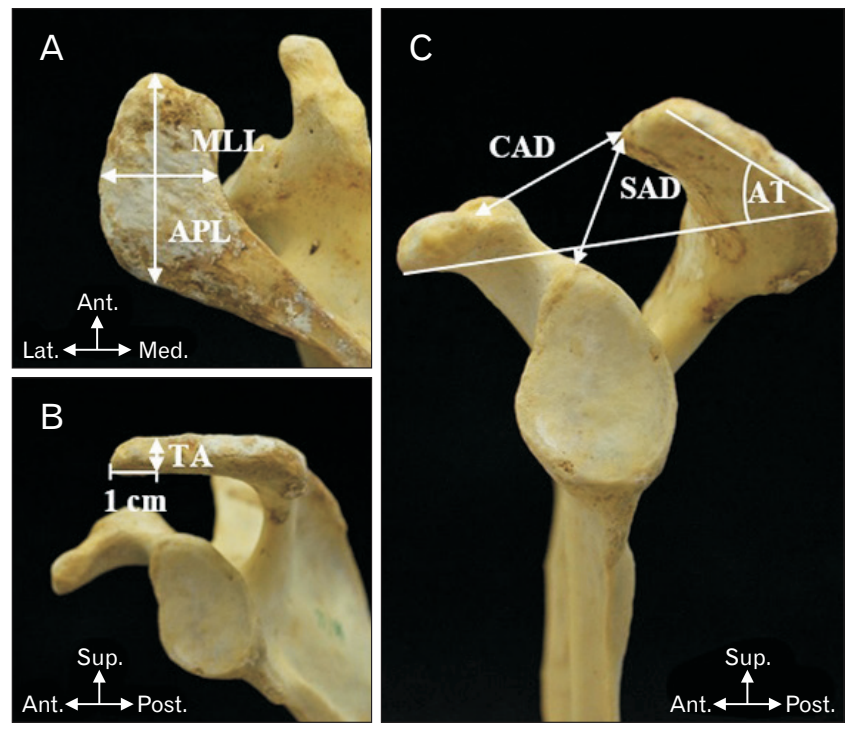

Fig. 1. (A) showed APL and MLL. (B) showed TA. (C) showed CAD, SAD, and AT. Ant., anterior; APL, maximum acromial length; AT, acromial tilt.; CAD, coracoacromial distance; Lat., lateral; Med., medial; MLL, maximum acromial width; Post., posterior; SAD, supraglenoacromial distanc; Sup., superior; TA, anterior one-third thickness. rameter was calculated in each age group, between sexes, and in total. The relationships among acromion type, acromial osteophyte, acromial parameters, age group, sex and side were demonstrated using descriptive and analytic statistics. Chi-square test, independent t-test and ANOVA were carried out as analytic statistics. Finally, all the data were analyzed to identify group of population at risk of subacromial impingement syndrome.

\section{Ethical statement}

The study protocol and ethics were approved by the Research Administration Section of Faculty of Medicine, Chiang Mai University, Thailand (No. EXEMPTION 7217/2563).

\section{Results}

The overall samples included in this study were 392 scapulae. The samples were stratified into 6 age groups, with 10 years in each age group, from the age of 31 to 90 . There were 32 samples in the age of 31 to 40,72 samples in the age of 41 to 50,72 samples in the age of 51 to 60,72 samples in the age of 61 to 70, 72 samples in the age of 71 to 80 , and 72 samples in the age of 81 to 90 . The mean age of samples was 62.92 years. The amount of left scapula was equal to the right, with 196 scapulae for each side. The number of male and female scapulae was 202 and 190, respectively.

According to Bigliani et al. [28] classification of acromion type as in Fig. 2, the curved acromion had the highest prevalence in total population. Its prevalence was $78.8 \%$. The second highest was hooked acromion for $12.0 \%$, and the last was flat acromion for $9.2 \%$. When stratified into age groups, the curved acromion also had the highest prevalence of all groups. The second was hooked acromion and the last was flat acromion. Except for the age of 31 to 40, the flat acromion had higher prevalence than the hooked acromion. Additionally, the prevalence of flat acromion in the age of 31 to 40
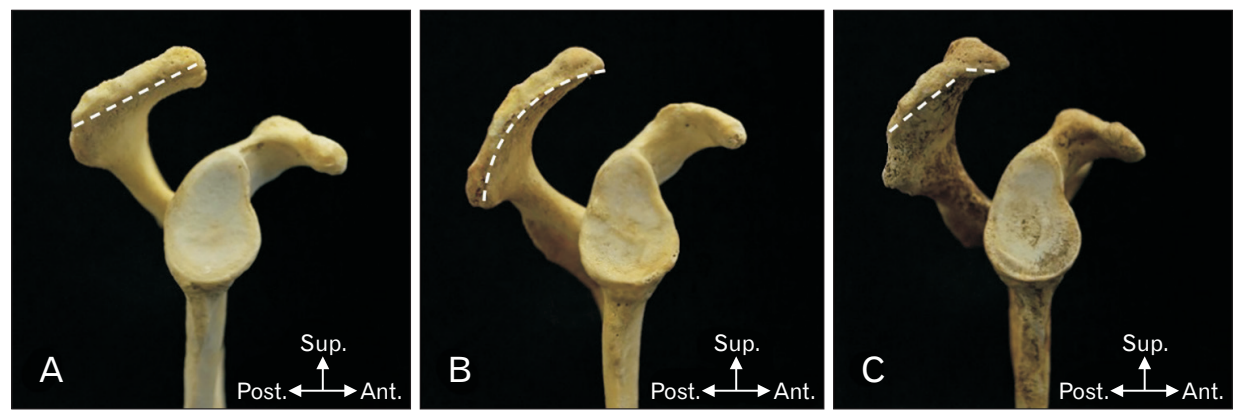

Fig. 2. Classification of acromion type; (A) Type I or Flat type, (B) Type II or curved type, (C) Type III or hooked type. Ant., anterior; Lat., lateral; Med., medial; Post., posterior; Sup., superior. 
was highest among all age groups (Fig. 3). The prevalence of hooked acromion was higher in male (15.3\%) than in female $(8.4 \%)(P<0.05)$. For flat and curved acromion, the prevalence in female ( $11.6 \%$ and $80.0 \%$, respectively) was higher than male $(6.9 \%$ and $77.7 \%$, respectively) but not statistically significant $(P>0.05)$.

The prevalence of osteophytes was 33.9\%, they were found

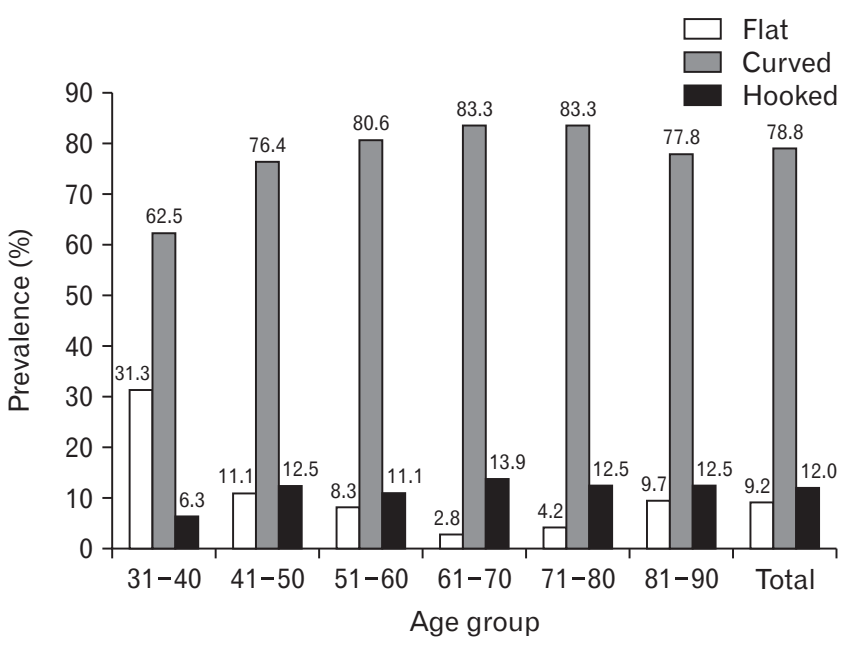

Fig. 3. Prevalence of acromion type in each age group.
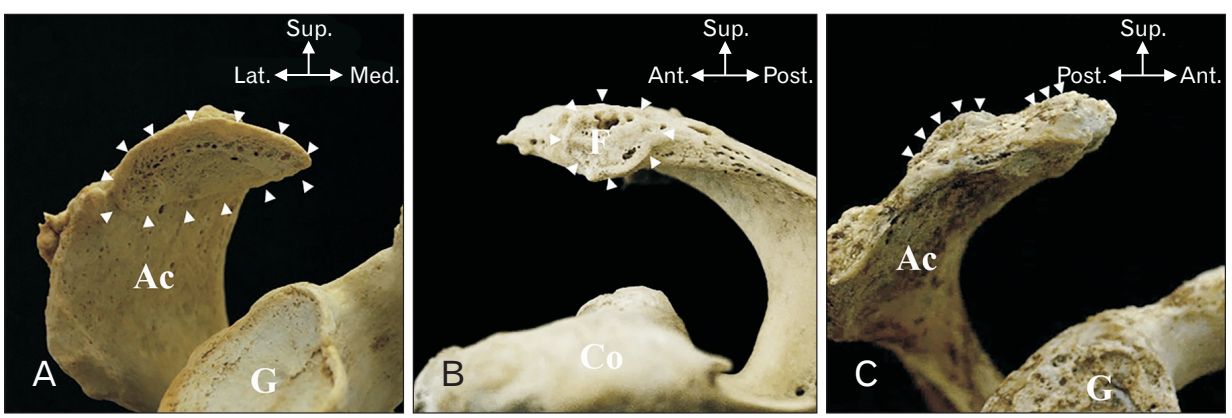

Fig. 4. Osteophyte location; (A) Anteroinferior surface, (B) Acromial facet, (C) Lateral surface. Ac, acromion; Ant., anterior; Co, coracoid; F, acromial facet; G, glenoid; Lat., lateral; Med., medial; Post., posterior; Sup., superior.

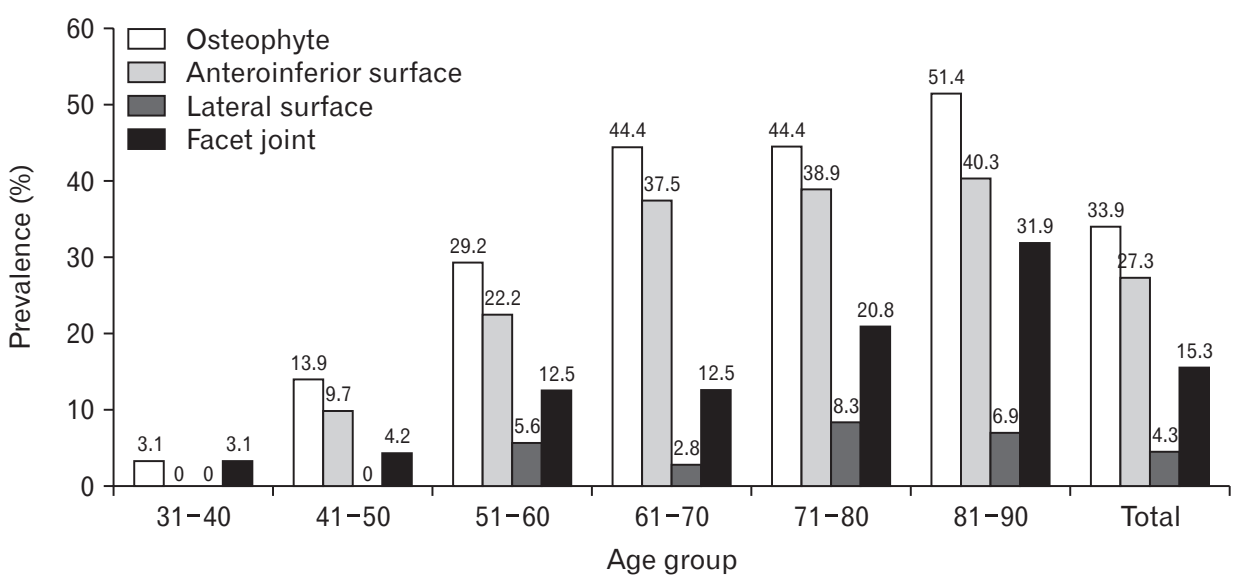

Fig. 5. Prevalence of acromial osteophyte in each age group. 
Mean of maximum acromial length (APL) and width (MLL) were 43.55 and $24.52 \mathrm{~mm}$, respectively. Mean of anterior one-third thickness of acromion (TA) was $8.53 \mathrm{~mm}$. Mean of CAD was $29.72 \mathrm{~mm}$ and mean of SAD was 25.96 $\mathrm{mm}$. Mean of AT was 28.1 degrees. When stratified into age group, mean of each parameter in each age group was close to mean of each parameter in total population. There were differences in male and female acromial parameters. All acromial parameters had higher value in male except for AT (Table 2).

ANOVA was used to find relationship of each parameter with age, and acromion type. TA and SAD values were significantly different among some age group. TA in the age of 31 to 40 was different from the age of 51 to $60(P<0.05), 61$

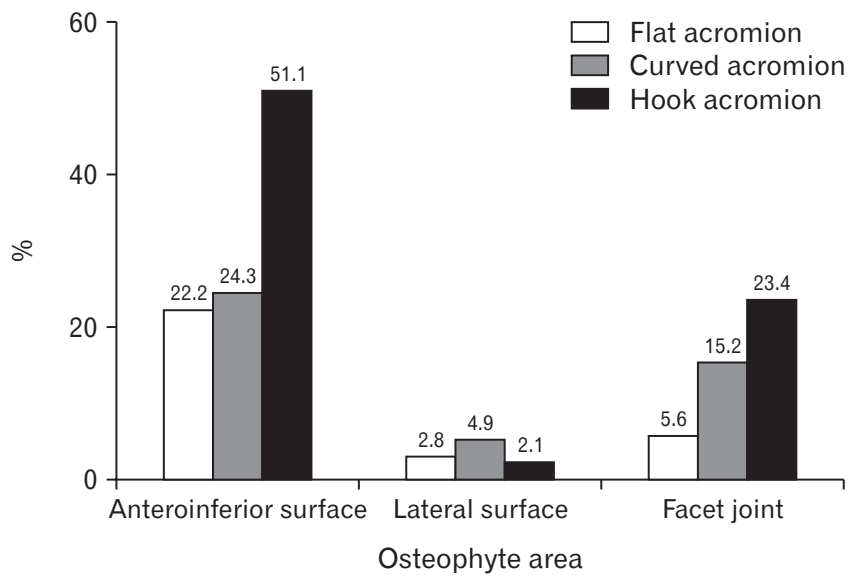

Fig. 6. Percentage of acromion type having osteophyte in each area. to $70(P<0.01), 71$ to $80(P<0.01)$, and 81 to $90(P<0.001)$. TA in the age of 41 to 50 was different from the age of 51 to 60 $(P<0.05), 61$ to $70(P<0.001), 71$ to $80(P<0.01)$, and 81 to 90 $(P<0.001)$. However, TA in the the age of 31 to 40 and 41 to 50 was not significantly different from each other $(P>0.05)$. SAD in the age of 81 to 90 was different from the age of 31 to $40(P<0.01), 41$ to $50(P<0.01)$ and 51 to $60(P<0.05)$. All acromial parameters, except $C A D$, were different among each acromion type. TA of hooked acromion was different from flat and curved acromion $(P<0.05)$. SAD and AT of hooked acromion were different from curved acromion $(P<0.01$ and $P<0.001$, respectively). Comparison of each acromial parameter between male and female, right and left side scapula were calculated by independent t-test. All male parameters were significantly different from female. When considering right and left side, there were 2 parameters, which were MLL and AT, that were significantly different between each side (Table 3).

Table 1. $P$-value of association between age group, sex, side, and acromion type

\begin{tabular}{lcccc}
\hline & $\begin{array}{c}\text { Age } \\
\text { group }\end{array}$ & Sex & Side & $\begin{array}{c}\text { Acromion } \\
\text { type }\end{array}$ \\
\hline Acromion type & $0.005^{\star}$ & $0.043^{*}$ & $0.040^{*}$ & - \\
Anteroinferior osteophyte & $<0.001^{*}$ & 0.348 & 0.125 & $<0.001^{*}$ \\
Lateral osteophyte & 0.096 & 0.706 & 0.079 & 0.618 \\
Facet osteophyte & $<0.001^{*}$ & $0.005^{*}$ & 0.546 & 0.081 \\
\hline
\end{tabular}

${ }^{\star} P$-value of 0.05 or less was considered statistically significant.

Table 2. Mean and standard deviation of each acromial parameter

\begin{tabular}{|c|c|c|c|c|c|c|}
\hline \multirow{2}{*}{ Parameter } & \multicolumn{2}{|c|}{ Male $(n=202)$} & \multicolumn{2}{|c|}{ Female $(n=190)$} & \multicolumn{2}{|c|}{ Total $(n=392)$} \\
\hline & Mean & SD & Mean & SD & Mean & $\mathrm{SD}$ \\
\hline Maximum acromial length (mm) & 46.66 & 4.08 & 40.25 & 3.36 & 43.55 & 4.93 \\
\hline Maximum acromial width (mm) & 26.09 & 3.06 & 22.85 & 2.98 & 24.52 & 3.42 \\
\hline Anterior one-third thickness (mm) & 9.28 & 1.70 & 7.72 & 1.42 & 8.53 & 1.75 \\
\hline Coracoacromial distance (mm) & 31.05 & 4.44 & 28.30 & 4.04 & 29.72 & 4.46 \\
\hline Supraglenoacromial distance (mm) & 27.07 & 3.25 & 24.77 & 3.11 & 25.96 & 3.38 \\
\hline Acromial tilt $\left({ }^{\circ}\right)$ & 27.60 & 4.90 & 28.70 & 4.90 & 28.10 & 4.90 \\
\hline
\end{tabular}

Table 3. $P$-value of relationships between each acromial parameters and age group, sex, side and acromion type

\begin{tabular}{|c|c|c|c|c|}
\hline Parameter & Age group $^{a)}$ & $\operatorname{Sex}^{\mathrm{b})}$ & Side $^{b)}$ & Acromion type ${ }^{a)}$ \\
\hline Maximum acromial length & 0.226 & $<0.001^{\star}$ & 0.120 & $<0.001^{\star}$ \\
\hline Maximum acromial width & 0.072 & $<0.001^{*}$ & $0.001^{*}$ & $<0.001^{*}$ \\
\hline Anterior one-third thickness & $<0.001^{*}$ & $<0.001^{\star}$ & 0.108 & $0.012^{*}$ \\
\hline Coracoacromial distance & $0.005^{*}$ & $<0.001^{*}$ & 0.614 & 0.459 \\
\hline Supraglenoacromial distance & $0.001^{*}$ & $<0.001^{*}$ & 0.475 & $0.005^{\star}$ \\
\hline Acromial tilt & 0.059 & $0.018^{*}$ & $<0.001^{*}$ & $<0.001^{*}$ \\
\hline
\end{tabular}

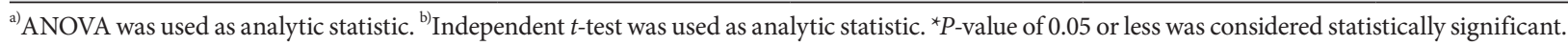


Table 4. Comparison of acromion type and osteophyte prevalence among studies

\begin{tabular}{|c|c|c|c|c|c|c|c|c|c|c|c|c|c|c|}
\hline \multirow{2}{*}{ Study } & \multirow{2}{*}{$\begin{array}{l}\text { Sample } \\
\text { size }(n)\end{array}$} & \multicolumn{4}{|c|}{ Flat acromion } & \multicolumn{3}{|c|}{ Curved acromion } & \multirow[b]{2}{*}{$\mathrm{AIS}^{\mathrm{a})}$} & \multicolumn{4}{|c|}{ Hooked acromion } & \multirow{2}{*}{ Osteophyte } \\
\hline & & Male & Female & Total & AIS $^{\text {a) }}$ & Male & Female & Total & & Male & Female & Total & $\mathrm{AIS}^{\mathrm{a})}$ & \\
\hline Guo et al. [15] & 292 & & & $47.3 \%$ & & & & $50.0 \%$ & & & & $3.0 \%$ & & \\
\hline El-Din and Ali [27] & 160 & & & $26.9 \%$ & & & & $58.1 \%$ & & & & $15.0 \%$ & & \\
\hline $\begin{array}{l}\text { Tangtrakulwanich and } \\
\text { Kapkird [30] }\end{array}$ & 302 & & & $84.5 \%$ & & & & $10.7 \%$ & & & & $4.6 \%$ & & \\
\hline Nicholson et al. [19] & 396 & & & $32.0 \%$ & & & & $42.0 \%$ & & & & $26.0 \%$ & $15.4 \%$ & $26.3 \%$ \\
\hline Banas et al. [29] & 100 & & & $39.0 \%$ & & & & $51.0 \%$ & & & & $10.0 \%$ & & $16.0 \%$ \\
\hline Alraddadi et al. [16] & 40 & & & $2.0 \%$ & & & & $55.0 \%$ & & & & $43.0 \%$ & $82.0 \%$ & $23.0 \%$ \\
\hline Natsis et al. [12] & 423 & & & $12.1 \%$ & $2.0 \%$ & & & $56.5 \%$ & $7.9 \%$ & & & $28.8 \%$ & $37.7 \%$ & $15.6 \%$ \\
\hline Paraskevas et al. [13] & 88 & $14.7 \%$ & $11.4 \%$ & $26.1 \%$ & & $29.5 \%$ & $26.1 \%$ & $55.6 \%$ & & $10.2 \%$ & $7.9 \%$ & $18.1 \%$ & $75.0 \%$ & \\
\hline Sangiampong et al. [20] & 154 & $1.9 \%$ & $6.4 \%$ & $3.2 \%$ & & $93.5 \%$ & $93.6 \%$ & $93.5 \%$ & $15.3 \%$ & $3.2 \%$ & $0 \%$ & $3.2 \%$ & $10.0 \%$ & $14.9 \%$ \\
\hline Current study & 392 & $6.9 \%$ & $11.6 \%$ & $9.2 \%$ & $22.2 \%$ & $77.7 \%$ & $80.0 \%$ & $78.8 \%$ & $24.3 \%$ & $15.3 \%$ & $8.4 \%$ & $12.0 \%$ & $51.1 \%$ & $33.9 \%$ \\
\hline
\end{tabular}

AIS, anteroinferior osteophyte of acromion.

${ }^{\text {a) }}$ Osteophyte prevalence on anteroinferior surface of acromion. ${ }^{\mathrm{b})}$ Total osteophyte prevalence.

\section{Discussion}

This study showed a trend of acromion type prevalence similar to previous studies, with curved acromion as the most common type $[12,13,15,19,20,27,29]$. Unlike Nicholson et al. [19], Banas et al. [29], Paraskevas et al. [13], El-Din and Ali [27], Guo et al. [15], hooked acromion is found overall more than flat acromion (Table 4). This difference may result from ethnicity and method of study. Bigliani et al. [28] and Morrison et al. [10] suggested that hooked acromion was most frequently associated with SAIS and rotator cuff tears. According to Tangtrakulwanich and Kapkird [30], patients with hooked type acromion had 6.2 times higher risk of developing SAIS than flat type. In this study, there were $12 \%$ of hooked acromion in total population, implying that oneeighth of the population had higher risk of developing SAIS. When considering sexes, acromion type was associated with sex, similar to Kadavkolan et al. [21] and Paraskevas et al. [13] $(P<0.05)$ (Table 4). Hooked acromion was found higher in male $(P<0.05)$. In addition, prevalence of hooked acromion was similar from the age of 41 to 90 , but a lot lesser in the age of 31 to 40 . Therefore, male with the age above 40 should be aware of having risk developing SAIS.

Acromial osteophyte was another important risk factor of SAIS. Osteophytes were found in $33.9 \%$ of acromions, more than Neer [8], Banas et al. [29], Nicholson et al. [19], Paraskevas et al. [13] (Table 4). This difference might be due to ethnicity and lifestyle. Thai population mostly had a lifestyle associated with agricultural work and manual labor requiring vigorous shoulder use. Anteroinferior surface is the area with highest prevalence of osteophyte in all acromion types. Only anteroinfeior surface osteophyte showed significant as- sociation with acromion type $(P<0.001)$. Similar to Natsis et al. [12], Paraskevas et al. [13], Alraddadi et al. [16], there were more anteroinferior osteophytes on hooked acromion than other types (Table 4). Other acromion types could turn into hooked type from excessive osteophyte formation on their anteroinferior surface. This result was consistent with Alraddadi et al. [16] whose observation of hooked acromion increased from $25 \%$ to $43 \%$ of specimens when acromial spurs were involved. Hooked acromion, as a primary structure (Fig. 2C), or as formed from osteophyte formation (Fig. 4A), had a higher chance of further anteroinferior osteophyte development which increased the risk of SAIS $[7,8]$. This study found that osteophyte formation on anteroinferior surface and acromial facet was associated with age $(P<0.001)$. Similar to Nicholson et al. [19], Mahakkanukrauh and Surin [17], Alraddadi et al. [16], advancing age showed increased osteophyte prevalence. Shoulder flexion and abduction promote inflammation on anteroinferior acromial surface by compression from humeral elevation and friction from supraspinatus movement $[2,5,7,9]$. Initially, there was subacromial bursa reducing the friction force. Over time, repetitive use of the shoulder caused chronic inflammation to the bursa, reducing its efficacy [18]. Additionally, the anteroinferior surface was also the insertion of coracoacromial ligament, a structure that degenerated with aging $[5,19]$. Inflammation around this surface makes it highly susceptible for osteophyte formation $[11,18]$. Acromial facet was the area with the second highest osteophyte prevalence. Osteophyte formation on facet could be triggered by acromioclavicular ligament degeneration $[19,24]$. Osteophytes on anteroinferior surface and acromial facet could narrow down subacromial space and possibly lead to the beginning of SAIS $[7,8,19,22]$. Lat- 
eral surface had the least prevalence of osteophyte and had no association with age $(P>0.05)$. It is possible to hypothesize that spurs on this area were caused by systemic inflammation or trauma instead of degenerative process. According to the age group, overall osteophytes in samples older than 50 years are 4 -fold more than samples younger than 50 years. This finding was consistent with Nicholson et al. [19]. Thus, people older than 50 years should be aware, since osteophyte formation became more common leading to higher risk of having SAIS. Repetitive shoulder activity should be avoided to prevent SAIS since 51 years old.

Association between side and acromion type showed statistical significance $(P<0.05)$, unlike Klasan et al. [25] findings. This implied that a person can have different acromion type in each side of shoulder. There is no association between side and acromial osteophyte areas, similar to the result of Alraddadi et al. [16] $(P>0.05)$. This finding suggests that both sides have equal risk of developing osteophyte. So, SAIS should be aware on both sides.

Morphometric evaluation of acromial parameters was carried out. When compared to other population groups, most acromial parameters were less than American, Greek and Nepalese populations, and more than Indian population $[13,14,19,31]$. Variation in body structures influenced by ethnicity could explain this difference, in which Caucasian have bigger shoulders than Asian [32]. The results of this study were mostly similar to Asian, which were Nepalese and Indian populations $[14,31]$. These results were expected to serve as basic reference parameters for SAIS operative treatment.

TA of acromion is a parameter that plays an important role in SAIS and its surgical treatment called acromioplasty, in which the anterior one-third of acromion is cut out [5, 29]. TA in samples younger than 50 years is different from samples older than 50 years $(P<0.05)$. From aging, acromion could become thicker by bone remodeling process [33]. Additionally, inflammation-induced osteophyte formation contribute to the rise of thickness. When considering the rise of TA in samples above 50-year-old as a contributing factor of SAIS, acromioplasty would be beneficial for patients who failed conservative treatment [5]. Good outcome had been reported for both open and arthroscopic acromioplasty [7, 8]. In patients younger than 50 years, other factors such as coracoacromial ligament hypertrophy could contribute to developing SAIS. In addition, acromion type is correlated with the outcome of conservative therapy and the need for surgical interference [34]. This study found that TA of hooked acromion was different from other types $(P<0.05)$. Accordingly, acromioplasty would be beneficial for SAIS patients who had hooked acromion.

SAD has a relationship with SAIS since impingement usually occurs vertically [35]. AT is also an important parameter affecting the vertical dimension of subacromial space. Li et al. [23] found that impinged patients had significantly smaller AT than control samples, implying that smaller AT increases risk of having SAIS. In this study, SAD and AT of hooked acromion are lower than curved acromion $(P<0.05)$. This result adds to the implication that people with hooked acromion should be aware of the risk of developing SAIS. According to age group, SAD in the age of 31 to 60 is greater than that of 81 to $90(P<0.05)$. The result may be associated with spur formation that increases with age. Other age group comparisons show no difference $(P>0.05)$. Contrarily, AT is not related to age $(P>0.05)$. So far, it is hard to stratify age group by risk using SAD and AT, since there are other factors affecting vertical subacromial space narrowing, such as abnormal elevation of humeral head $[1,5,7,9,24]$. Radiograph is necessary for further study on this topic.

This study demonstrated that there are significant differences in all parameters between sexes, but not side $(P<0.001$ and $P>0.05$, respectively). Consideration should be made with the fact that male have greater muscle mass attaching to the bone causing greater skeletal robusticity than female [36]. Male TA differs from female, with male having thicker anterior one-third acromion $(P<0.05)$. Although greater SAD was noted in men, male AT was smaller $(P<0.05)$. Ultimately, greater TA and smaller AT suggest that male has a higher chance of developing SAIS, corresponding to male reported as predominant sex in the incidence of SAIS [37]. This result was also in consistent with the association of acromion type and sex influencing impingement risk as mentioned previously.

Nevertheless, several limitations need to be acknowledged in this study. For instance, the result can only be applied to Thai population and those that are similar to Thai. There are many conflicting results compared with previous studies. Future research should concentrate on summarizing all different results using statistical analysis to establish a single conclusion.

In conclusion, general population with chronic shoulder pain at the age above 50 should be investigated for SAIS. In concerned male groups with chronic shoulder pain, such as 
repetitive shoulder users, investigation for SAIS should be performed at the age above 40 . These groups of patients have a higher chance of conservative treatment failure because hooked acromion and osteophytes are mostly the root of the problem. Surgical treatment is recommended in these groups. Radiographic study should be carried out to look for surgically correctable causes. Initially, X-ray should be performed in two views. First, the supraspinatus outlet view to determine type and the presence of anteroinferior osteophyte. Second, the anteroposterior view to determine the presence of facet osteophyte. If X-ray finding is unremarkable, CT scan or MRI should be considered as the next investigation.

\section{ORCID}

Thawanthorn Chaimongkhol:

https://orcid.org/0000-0002-0175-4723

Sirapat Benjachaya:

https://orcid.org/0000-0001-5290-9249

Pasuk Mahakkanukrauh:

https://orcid.org/0000-0003-0611-7552

\section{Author Contributions}

Conceptualization: TC, SB. Data acquisition: PM. Data analysis or interpretation: TC, SB. Drafting of the manuscript: TC, SB. Critical revision of the manuscript: PM. Approval of the final version of the manuscript: all authors.

\section{Conflicts of Interest}

No potential conflict of interest relevant to this article was reported.

\section{Acknowledgements}

This study was funded by the Faculty of Medicine, Chiang Mai University, Chiang Mai, Thailand. We would also like to thank the Excellence in Osteology Research and Training Center (ORTC) with partially supported by Chiang Mai University. The author would also like to thank to those who donated the body for study and research.

\section{References}

1. Garving C, Jakob S, Bauer I, Nadjar R, Brunner UH. Impingement syndrome of the shoulder. Dtsch Arztebl Int 2017;114:76576.

2. De Yang Tien J, Tan AHC. Shoulder impingement syndrome, a common affliction of the shoulder: a comprehensive review. Proc Singapore Healthc 2014;23:297-305.

3. Juel NG, Natvig B. Shoulder diagnoses in secondary care, a one year cohort. BMC Musculoskelet Disord 2014;15:89.

4. van der Windt DA, Koes BW, de Jong BA, Bouter LM. Shoulder disorders in general practice: incidence, patient characteristics, and management. Ann Rheum Dis 1995;54:959-64.

5. Blom AW, Warwick D, Whitehouse MR. Apley and Solomon's system of orthopaedics and trauma. 10th ed. Boca Raton: Taylor \& Francis; 2018.

6. Lazaro R. Shoulder impingement syndromes: implications on physical therapy examination and intervention. J Jpn Phys Ther Assoc 2005;8:1-7.

7. Dhillon KS. Subacromial impingement syndrome of the shoulder: a musculoskeletal disorder or a medical myth? Malays Orthop J 2019;13:1-7.

8. Neer CS 2nd. Anterior acromioplasty for the chronic impingement syndrome in the shoulder: a preliminary report. J Bone Joint Surg Am 1972;54:41-50.

9. Edwards SL, Bell JE, Bigliani LU. Subacromial impingement. In: Wilk KE, Reinold MM, Andrews JR, editors. The Athlete's Shoulder. 2nd ed. Philadelphia: Churchill Livingstone; 2009. p.115-22.

10. Morrison DS, Frogameni AD, Woodworth P. Non-operative treatment of subacromial impingement syndrome. J Bone Joint Surg Am 1997;79:732-7.

11. Nyffeler RW, Meyer DC. Acromion and glenoid shape: why are they important predictive factors for the future of our shoulders? EFORT Open Rev 2017;2:141-50.

12. Natsis K, Tsikaras P, Totlis T, Gigis I, Skandalakis P, Appell HJ, Koebke J. Correlation between the four types of acromion and the existence of enthesophytes: a study on 423 dried scapulas and review of the literature. Clin Anat 2007;20:267-72.

13. Paraskevas G, Tzaveas A, Papaziogas B, Kitsoulis P, Natsis K, Spanidou S. Morphological parameters of the acromion. Folia Morphol (Warsz) 2008;67:255-60.

14. Mansur DI, Khanal K, Haque MK, Sharma K. Morphometry of acromion process of human scapulae and its clinical importance amongst Nepalese population. Kathmandu Univ Med J (KUMJ) 2012;10:33-6.

15. Guo X, Ou M, Yi G, Qin B, Wang G, Fu S, Zhang L. Correction between the morphology of acromion and acromial angle in Chinese population: a study on 292 scapulas. Biomed Res Int 2018;2018:3125715.

16. Alraddadi A, Alashkham A, Lamb C, Soames R. Examining changes in acromial morphology in relation to spurs at the anterior edge of acromion. Surg Radiol Anat 2019;41:409-14. 
17. Mahakkanukrauh P, Surin P. Prevalence of osteophytes associated with the acromion and acromioclavicular joint. Clin Anat 2003;16:506-10.

18. Umer M, Qadir I, Azam M. Subacromial impingement syndrome. Orthop Rev (Pavia) 2012;4:e18.

19. Nicholson GP, Goodman DA, Flatow EL, Bigliani LU. The acromion: morphologic condition and age-related changes. A study of 420 scapulas. J Shoulder Elbow Surg 1996;5:1-11.

20. Sangiampong A, Chompoopong S, Sangvichien S, Thongtong P, Wongjittraporn S. The acromial morphology of Thais in relation to gender and age: study in scapular dried bone. J Med Assoc Thai 2007;90:502-7.

21. Kadavkolan AS, Lehmann LJ, Reichert M, Lattka K, Moursy M. Does acromion morphology depend on the extremity or on gender in the population? J Comput Assist Tomogr 2017;41:1214.

22. Pesquer L, Borghol S, Meyer P, Ropars M, Dallaudière B, Abadie P. Multimodality imaging of subacromial impingement syndrome. Skeletal Radiol 2018;47:923-37.

23. Li X, Xu W, Hu N, Liang X, Huang W, Jiang D, Chen H. Relationship between acromial morphological variation and subacromial impingement: a three-dimensional analysis. PLoS One 2017;12:e0176193.

24. Roidis NT, Motamed S, Vaishnav S, Ebramzadeh E, Karachalios TS, Itamura JM. The influence of the acromioclavicular joint degeneration on supraspinatus outlet impingement and the acromion shape. J Orthop Surg (Hong Kong) 2009;17:331-4.

25. Klasan A, Malcherczyk D, Neri T, Saul J, Schofer MD, Heyse TJ, El-Zayat BF. Reporting on acromion morphology: classifications demonstrate significant correlation. J ISAKOS 2020;5:837.

26. Maalouly J, Tawk A, Aouad D, Abdallah A, Darwiche M, Abboud G, El Rassi G. Association of acromial morphological parameters and rotator cuff tears, and evaluation of the influence of age and gender on the parameters and impact on cuff tears: a study on a Middle Eastern population. Asia Pac J Sports Med
Arthrosc Rehabil Technol 2020;20:17-23.

27. El-Din WA, Ali MH. A morphometric study of the patterns and variations of the acromion and glenoid cavity of the scapulae in Egyptian population. J Clin Diagn Res 2015;9:AC08-11.

28. Bigliani LU, Morrison DS, April EW. The morphology of the acromion and its relationship to rotator cuff tears. Orthop Trans 1986;10:228.

29. Banas MP, Miller RJ, Totterman S. Relationship between the lateral acromion angle and rotator cuff disease. J Shoulder Elbow Surg 1995;4:454-61.

30. Tangtrakulwanich B, Kapkird A. Analyses of possible risk factors for subacromial impingement syndrome. World J Orthop 2012;3:5-9.

31. Saha S, Vasudeva N. Morphometric evaluation of adult acromion process in North Indian population. J Clin Diagn Res 2017;11:AC08-11.

32. Cabezas AF, Krebes K, Hussey MM, Santoni BG, Kim HS, Frankle MA, Oh JH. Morphologic variability of the shoulder between the populations of North American and East Asian. Clin Orthop Surg 2016;8:280-7.

33. Adamopoulos IE. Inflammation in bone physiology and pathology. Curr Opin Rheumatol 2018;30:59-64.

34. Wang JC, Hatch JD, Shapiro MS. Comparison of MRI and radiographs in the evaluation of acromial morphology. Orthopedics 2000;23:1269-71.

35. Aragão JA, Silva LP, Reis FP, Dos Santos Menezes CS. Analysis on the acromial curvature and its relationships with the subacromial space and types of acromion. Rev Bras Ortop 2014;49:636-41.

36. Haizlip KM, Harrison BC, Leinwand LA. Sex-based differences in skeletal muscle kinetics and fiber-type composition. Physiology (Bethesda) 2015;30:30-9.

37. Tekavec E, Jöud A, Rittner R, Mikoczy Z, Nordander C, Petersson IF, Englund M. Population-based consultation patterns in patients with shoulder pain diagnoses. BMC Musculoskelet Disord 2012;13:238. 